\title{
Equity, Inclusion, and Beyond: Today's Urban Chief Diversity Officer
}

\author{
Merodie A. Hancock
}

New forms and shapes of education are the necessary ingredients that can make the substance of education and educational processes more relevant to the individual and more responsive to the needs of society.” Bonnabeau, Richard F. (1996) “The Promise Continues: Empire State College, The First Twenty-Five Years

Keywords: graduation-rate disparities; inclusive campus culture; inequity in access; college completion; underserved students; pluralism in the classroom; stop- or drop-out rate; campus gestalt

\begin{abstract}
This paper, based primarily on the author's perspective as president of SUNY Empire State College, will explore the need for, and means of leveraging, the chief diversity officer's role in creating an equitable and inclusive environment within the distributed world that is Empire State College’s “campus” and, specifically, within SUNY Empire’s urban environments. Empire State College fills a unique role in today's higher-education landscape. It was founded in 1971 by Ernest Boyer, then the chancellor of the State University of New York, to make education accessible outside the confines of traditional curricular and delivery structures, and to better meet the needs of New Yorkers with locations, academic programming, and student services responsive to diverse communities and learners. Today, Empire State College continues to embrace and fulfill that mission, with individualized education as its cornerstone and nearly 18,000 undergraduate and graduate students in 34 academic centers around the state of New York, in several countries overseas and online around the world. The vast majority of its undergraduate students have attended at least one previous institution, are employed, and are likely to have family and dependent-care obligations. The college is purposefully nonresidential, designed to be where our students live and work. Students can choose structured or individualized academic programs, depending on discipline, and have the options of classroombased, online, or independent study, as well as weekend residencies, or a hybrid of education delivery via these modes.
\end{abstract}

\section{Introduction}

Empire State College hired our first Chief Diversity Officer for Equity and Inclusion in 2016, partly to respond to a system-wide policy but more to ensure we continuously grow and fulfill our mission. As a president, I believe pluralism cannot be achieved until an institution first accepts and integrates diversity into its fabric. With diversity can come equity and inclusion, and only when you have fully embraced all three can pluralism find its roots as a shared value. A good chief diversity officer-in partnership with the college president, provost and cabinet—can progress an institution through each of these levels to a point where mission is melded with practice, empowering all its students to grow and achieve economic independence as a way to 
build and improve their diverse communities. Yet, the work is never done. Even for colleges founded on the premise of equitable and available education for all, the urban environment continues to change and colleges face new challenges daily that can quickly undermine even the strongest diversity, inclusion and pluralist foundations.

\section{The Broader Context}

With equity, accessibility, personal growth and self-empowerment for all learners at the core of its mission, Empire State College reaches students in outlying rural communities, small towns, medium-size cities, and major metropolitan areas. It is sited strategically across New York to serve the more populous areas, where large numbers of SUNY Empire's students live and work, as well as the more remote communities, where conventional educational opportunities are limited. The college therefore prides itself on meeting students where they are, academically, professionally, personally, and geographically. The college's presence within the integrated communities it serves creates a rich tapestry of students, faculty, and staff, who are diverse in age, race, religion, gender, sexual identity, socioeconomic and marital status, political affiliation, educational background, physical ability, as well as other characteristics, experiences, and cultural influences. The combination of Empire State College's dispersed footprint, inclusive mission and progressive outreach promote a vibrancy that embraces pluralism, not homogeneity, in its community and its pedagogy. As such, our goal is to ensure we constantly strive to improve and hold ourselves accountable to these standards in today's fast paced, dynamic and often contentious world.

The greatest proportion of SUNY Empire's student body resides in the most densely populated areas served by the college, particularly greater Metropolitan New York, as well as Buffalo, Rochester, Syracuse, and the Capital Region. Therefore, while the chief diversity officer supports the college as a whole, we chose to locate this position within New York City where we have a significant amount of student and faculty activity. By virtue of location, these Empire State College students reflect the demographics of many large urban centers in the United States, including a stronger presence (relative to nonurban areas within New York) of underrepresented groups within higher education. Often, these urban groups reside in highly populated low- and middle-income neighborhoods with people of like backgrounds, with whom they share a language, values, food preferences, religion, social norms, customs, traditions, and other familiar and common interests and activities. These overwhelmingly minority and immigrant urban communities often have not yet acquired adequate social, academic, and financial capital. Their neighborhoods, including their schools, often are under-sourced in terms of government allocated funds, infrastructure, and services, which discourages community activism that could steer positive change. This leads, instead, to a cycle of handicapping that drives academic, health, and political disempowerment, from generation to generation. To put this in terms of baseline academic impact, across the U.S., "Only about one-half (52\%) of students in the principal school systems of the 50 largest cities complete high school with a diploma. That rate is well below the national graduation rate of 70\%." (Swanson, C.B. 2008. "Cities in crisis: A special analytic report on high school graduation.”)

The Chronicle of Higher Education broadens this picture in its report on college completion, (http://collegecompletion.chronicle.com/state/\#state=ny\&sector=public_four), which, while not 
broken down by largest cities, reflects the all-too-common racial degree-completion disparity. In New York State, in 2013, 44.7\% of white students who first attended school full time graduated in four years, compared to $24.1 \%$ of black students, $36.2 \%$ of Asian students, $22.6 \%$ of Hispanic students and $28.2 \%$ of Native American students. Moreover, at the six-year mark, $63 \%$ were white, $46.8 \%$ were black, $67.9 \%$ were Asian, $46.5 \%$ were Hispanic and $48.2 \%$ were Native American. While, technically, these and most other traditional college-completion studies exclude the majority of Empire State College students, where students are largely part time and bring in transfer credit, the trends resonate all too painfully.

Combining high-school graduation rates within the nation's largest cities with colleges' graduation-rate disparities among racial groups, then factoring in the projected population growth of New York City, other large cities, and the collective growth of minority populations, makes clear that in order to make progress, the status quo must be disrupted. The historic pattern of inequity in educational access, resources, and achievement will further deteriorate the economic, social, mental, physical, and overall community health of America's large cities. However, degree completion cannot be the measure of success without significant attention paid to how these underserved populations experience the U.S. education systems. The chief diversity officer can and should play a key role in planning and executing this productive disruption. Successfully influencing the education-equity equation cannot be treated simply by what is often described as the "massification" of education through increased access.

Massification often is based on the assumption that a college degree will, in itself, level the playing field and eliminate other socioeconomic discrepancies. This simply is not the case. The diversity of current and potential college students is not representative of just race, gender and other common factors. Rather, it comprises: (a) multiple native and home-spoken languages; (b) disparate levels of academic preparedness and confidence; (c) unequal exposure to the arts, travel, literature, politics, civic responsibilities, powerful or connected social contacts; and (d) more inequities that weave singularly and collectively through the common "check box" definitions of diversity. For academic attainment to have a long-term equalizing and empowering effect on populations that are currently underserved, colleges and their chief diversity officers must go beyond measuring degree attainment and address the need for equity and appreciation at the individual student level, at each stage of his or her academic and professional career. In much the same spirit that Empire State College was founded nearly 50 years ago, the college still strives to break down rigid admission, curricular and delivery barriers. In the process we seek to challenge blatant and tacit beliefs within the K-12 and higher education orthodoxy. Furthermore, we create learning environments that identify and thrive on student differences and reinvest in each college student as a capable and deserving individual learner. Moreover, we seek to build college communities into living, learning classrooms that consistently promote the overwhelming benefits of pluralism.

This work is not easy nor fast. It can only be achieved if we expand our expectations for the work of chief diversity officers beyond such tactical areas as compliance tracker, trainer, problem resolver, recruiter, student affairs and human resources expert, activities planner, legal analyst, grant writer and so on. More often than not, they are but one person, with little to no staff, resources, or direct authority. Yet, at a minimum, they are expected to develop and maintain a college culture that proactively meets current compliance and regulatory standards. 
More inspirationally, the new culture for which they strive must support and value diversity, inclusion, and pluralism throughout all aspects of the college's environment.

Chief diversity officers often attempt to win a game where the players and rules keep changing. All too often, a new CDO quickly assumes a reactive tactical mode, spending time putting out fires and filing reports, rather than being able to focus on becoming an integral part of the college fabric, or sowing the seeds, through strategy and resource allocation, for sustainable, equitable, and inclusive learning environments that benefit both targeted populations and the college community as a whole. This matters in the long term and beyond the campus, because, ultimately, the college community flows into a larger society, within which the people who comprise it live, work, study, serve, volunteer, vote, spend leisure time, fuel the economy, and raise their children. The balance of this paper, based primarily on the author's perspective as president of SUNY Empire State College, will explore the need for and means of leveraging the chief diversity officer's role in creating an equitable and inclusive environment within the distributed world that is Empire State College's “campus” and, specifically, within SUNY Empire's urban environments.

\section{Meeting Students Where They Are}

Like other colleges, Empire State College tracks recruitment, retention, and graduation rates across gender and race and, as part of a larger State University of New York initiative, is working to track similar metrics on multiple other self-declared personal identifiers. Having this quantitative data is invaluable in identifying areas for further review. Fortunately, the college's data shows it performing better than many peer access institutions. Unfortunately, the same way data can identify red flags, it can also lull campus leadership into complacency. College curricula are well thought out, comprehensive collections of learning objectives and experiences that help equip graduates for career growth and community engagement. However, as colleges build these curricula and strive toward common learning outcomes for all students, it is all too easy to build upon the fallacy that students will bring relatively similar sets of academic and life experiences, as well as learning styles, when they enter college. In part, this reflects the fact that, while faculty diversity is growing, it remains largely homogenous, populated by middle- and upper-class traditionally educated scholars. As a result, the development, delivery and learning-assessment protocols of academic programs can be foreign to, and even at odds with, the interests and experiences of diverse and underrepresented student and faculty populations. Even the bestintentioned educator cannot presume to fully understand a student's or colleague's unique life circumstances.

Most Empire State College students are in their 20s, 30s, or 40s; many are first-generation college students, have a family, work, and aim to improve their economic and professional futures. Institutions like Empire State College that serve nontraditional students often assign a large portion of the blame for why students drop out and/or stop out to "life gets in the way." This category encompasses numerous family issues, personal illness, job change or loss, competing demands for limited time and money, etc. It is also the category the college uses when the reason a student has left is not known. The "life gets in the way" bucket has become the presumptive excuse for situations perceived as out of the college's control. Moreover, "life gets in the way” is the dominant reason identified for drop- and stop-outs within Empire State 
College's urban, underserved student populations. Therefore, it is critical that Empire State College, and urban access colleges as a whole, assume a proactive and disruptive role and "get in the way of life" for these students. This is exactly where Empire State College is focusing our efforts. Collectively with the chief diversity officer, leadership, faculty and staff, we are striving to assist urban students effectively with each person at each point of contact, listening attentively to each student to understand, in detail, where they are and what challenges they may encounter. We are engaging a college-wide cadre of human resources who understand the many ways life can get in the way for these students, and systematically examining how the gestalt of the campus community can better support learning and student success for all learners.

\section{The Double Life of the Urban Student}

The current model of U.S. higher education vastly skews toward students, faculty, and staff from families where academic credentials are highly regarded and supported. Perceptions and support structures are built around students who graduate high school and progress directly to college, where they study full time, as well as work or engage in extracurricular activities. Their families and communities value a college education and typically provide emotional and financial support. Educators often operate under the assumption that all students have this same support system. However, urban students are often commuters, work full time to pay their bills, and try their best to fit school into their already busy lives, commitments and responsibilities. They often live among relatives, friends and neighbors who might not understand, appreciate or support their academic aspirations. This creates the challenge of negotiating two worlds: the aspirational, upwardly mobile life of a student versus a home life that revolves around fitting in, traditions, family, or social responsibilities, and acceptance of the status quo. Empire State College's NYCbased director of academic support describes this bifurcated life:

Our urban cohort students are commuters with a lot going on in their lives. They go to class and to work, where they experience diversity, and then go back home, where it's 'all Greek' all the time, as it was for me, or Italian, or Puerto Rican, or whatever. It makes it very hard for them to engage in college life.

In this vein, some SUNY Empire students shared that they could not study at home and that their academic pursuits were not supported by family or friends. Others shared that they are teased at home when they use "school” or "uppity" proper English, so they do not practice. For these students, one or two General Education English requirements will not overwrite 30 years of improper English spoken at home and work.

The urban chief diversity officer can help a college understand how this double life adds an additional level of pressure to students already at risk. Colleges may need to build in purposeful conversation times, where new communications skills are practiced, while helping students understand the value of building these and other professional communication skills. Similarly, assuming all students will be able to go home and complete their assignments or study with other classmates may be misguided. Providing space and time for ongoing student interactions is vital in creating different types of inclusive support groups for urban commuter students. Unlike the student's home community that may (intentionally or unintentionally) undermine academic success, a healthy student peer group will push students to complete homework, discuss a topic 
of interest, understand issues from other students' perspectives, and provide needed encouragement if a member of the group wants to leave school. Conversely, students with permanent or situational mental, intellectual, emotional, or physical challenges may not be comfortable disclosing their conditions, but may be more responsive to increased access to materials, faculty, and staff virtually, or in one-to-one settings. These types of considerations are understood by chief diversity officers, but, perhaps, not fully appreciated by others.

Traditionally, the chief diversity officer may not be asked to weigh in on building hours, design, staffing, and virtual resources; however, it may, in fact, be the one office that has the most global perspective on what is needed for this growing population of students.

\section{Different Ways of Knowing and Learning}

Empire State College was founded on a purposeful faculty mentoring model and prides itself on knowing students as they are, while actively engaging them throughout all aspects of the learning process-though as noted, we challenge ourselves to continuously improve. A requirement in the admissions process is for undergraduate students to reflect, in a short essay, on where they have been academically, where they want to go and why and how they are going to make that happen. At Empire State College, a faculty mentor is partnered with each student, from admission through graduation. These mentors go well beyond the traditional academic advisor role by reviewing the admissions essay and then working with each student to build the student's degree plan. This plan will take into account what the student will study, what he or she may already know and, often, how he or she will overcome potential obstacles from their personal and professional lives. Every faculty mentor is expected to have a sense of his or her students' unique personal and academic goals, as well as personal and academic challenges. When the relationship works, it creates a mutually respectful relationship and establishes the cohesion that results in students feeling valued by the institution and continuously engaged in their education and the college.

However on the rare occasion when it does not work, the student's overall relationship with the college can feel unwelcoming, and both academic performance and the sense of inclusion may suffer. This is an area where the chief diversity officer is strategizing with faculty and college administration to identify improvements in the student-mentor match process, strengthen the college's professional development resources and improve processes for early problem identification and mentor reassignment when needed. Interestingly, the students' perceptions and the college's data agree that it does not matter if the faculty mentor shares an ethnic, racial, sexual identity, or other known group membership commonality. Rather, the success of this mentor-student relationship appears to be based on something less quantifiable. According to a small sample of SUNY Empire students, the success of the primary mentor relationship is frequently determined within the first or second meeting and is contingent on a shared sense of personal understanding, respect, and commitment to that student's particular academic journey.

In addition to access to faculty mentors, the college has created numerous other opportunities for learning support throughout the college. Similar to the findings on the impact of the studentmentor relationship, internal research has found that positive initial meetings with learning support staff greatly influence the student's willingness to continue his or her studies and stay actively engaged with the college. We believe these individualized faculty mentor and learning 
support models are at the heart of the college's consistently high student satisfaction ratings (per the ACT Student Opinion Survey administered triennially for the State University of New York) and higher than peer completion rates. However, there is always room for improvement, particularly with underrepresented college completion populations.

While other urban colleges may not share Empire State College's commitment to individualized learning, it is critical that they understand the multiple ways a student may learn and know. The potential lack of learning supports in college, primary and secondary school and, in some cases, the home environment often and mistakenly is conflated with students' intelligence and capability. Similarly, nontraditional and underrepresented students can be unconsciously assigned a "less intelligent" label by misguided faculty and staff. At Empire State College, personal statements from students, as well as ongoing discussions with faculty and staff, help ensure each student is respected for his or her own ways of learning and knowing. In the words of one faculty member,

The faculty must understand there are diverse ways of teaching students who have, themselves, diverse ways of knowing. We talk about students "pulling themselves up by their bootstraps", well, we may have to give them the boots. Our job is to meet his or her needs, level the playing field and treat everyone fairly. This doesn't just mean global awareness of diversity, but also awareness of each individual's differences and what he or she needs to know and how, as a mentor, to teach it. There may be differences in how students learn, based on what they already know or perceive, learning style or cultural information. Access goes hand-in-hand with inclusion and that means helping people feel they belong and welcoming them, through open doors, into the urban ecosystem, which should include higher education. This is not something faculty members normally learn in their own education. The chief diversity officer can be a proactive force at new-faculty orientation and with ongoing professional development initiatives to help our urban faculty and colleges better understand how to level the educational playing field before the student even walks onto it.

\section{Building Appreciation}

While today's chief diversity officers need to play a more proactive role in building and operating urban colleges by helping them identify strategies and resources to address diverse students at the individual level, the CDO also plays a vital role in educating the broader community on the social and economic values of inclusion, equity, and pluralism. At Empire State College, the chief diversity officer strives to help faculty and staff understand how college policies, as well as college and individual practices, may support or undermine the learning goals of underserved and diverse students. From how the student is greeted, in person, on the phone, online or in writing to the hours we are open, the resources we use and the assumptions we make, the chief diversity officer should have a lens across the institution from multiple perspectives. As CDOs too come from one background, our CDO engages other voices and perspectives across the college to broaden that lens and strengthen the college's cultural awareness. As Empire State College is a part of the SUNY system, the CDO also works with the president's office as well as SUNY system offices and others to roll up the needs of individual students to a broader message of community and economic appreciation and empowerment. 
Conscious and unconscious biases exist in everyone and no one can ever fully appreciate the walk in another's shoes, including and especially detractors who imply that inclusion and equity means lowering academic standards, taking resources away from the overall college community and/or making exceptions to learning expectations. Colleges with strong access missions struggle every day to balance the increasing range of needs of incoming students with the goal of increasing degree attainment rates and strengthening the college community, while living in a world of limited resources. Colleges such as Empire State College always will roll out the welcome mat for diverse students and strive to improve completion rates, while maintaining the academic standards that make graduates proud and successful. Paradoxically, when studentsuccess risk factors go up, as is the case for access-oriented institutions, public resources tend to go down. When colleges face declining budgets and increasing student needs, there is a tendency to focus on the homogenous majority to drive up student success metrics, while minimizing budget impact. Those who lead colleges with access missions often speak of the challenge between staying true to the mission and meeting the budget and regulatory realities. It takes a certain alchemy to integrate the many paths a student may take before coming to the college with the set of learning outcomes and personal development he or she should have at graduation. The more heterogeneous the student population, the more challenging and rewarding this can be. Despite the stress of tight budgets and demand for higher degree-completion rates, colleges cannot understate the value of diversity in strengthening college communities, graduates, and the workforce they enter.

Beyond increasing degree attainment, urban hubs of diverse student, faculty and staff foster the potential for incubators of pluralism, promulgating the value of coexistence and mutual support, while building an interdependent ecosystem. Building on concepts of diversity, inclusion, and equity, college and university chief diversity officers should aspire toward another, more comprehensive level of opportunity, even beyond equity. This is an aspirational, though this author believes very logical, goal that the chief diversity officer cannot accomplish alone. However, they can identify and build on pockets of support. The argument can be made from social, economic, health, religious, and other fronts. The chief diversity officer should identify, understand and promulgate the college- and society-wide value of inclusive and holistic student success. Singing to the choir cannot be the primary tactic, though that is all too often the approach.

The strategic CDO will work across the college community to understand the various perspectives and find areas of mutual value. From program and course design to extracurricular activities and professional development, urban colleges should be called upon to move the needle from equity to mutually beneficial, universally appreciated coexistence. This is yet another challenge to urban schools, the chief diversity officers who serve them, and the presidents who lead them. As campuses further integrate and better represent the world at large, the need has, perhaps, never been greater to go beyond opening doors to diversity, equity and inclusion and move to instilling the value of pluralism, in building societies, driving businesses, developing public policy, and more. Presidents and chancellors must work together to collectively and continuously make this case from an objective, data-informed basis that ties equity, inclusion, and pluralism into lasting economic and community health. 


\section{Conclusion}

Today's urban and access-oriented college chief diversity officers, in partnership with their presidents, provosts, boards, and councils, are responsible for continuously educating the extended academic, political, and professional communities on the broader investment value of diversity, inclusion, equity, and pluralism initiatives. Educators have learned, repeatedly, that increased educational attainment empowers communities, drives civic responsibility, propels economic development and wealth, reduces crime and recidivism, improves personal and community health, powers entrepreneurism, and strengthens schools, and the list goes on. The chief diversity officer must play an important role in advocating both inside the college community and with external partners among the local and federal governments, employers, $\mathrm{K}$ 12 school districts, and other civic organizations. Investing in academic programs that meet students where they are can help the institution "get in the way of life" to offset the demanding commitments on students and alleviate some of the community pressures experienced by diverse populations. Such action yields both immediate and long-term impacts that need the authentic and continuous support and understanding of civic, political, business, and academic leaders to succeed. Institutionalizing this type of individualized equity-based programming and pluralismbased college culture will require a comprehensive strategy, time and resources, but as more and more educated students become leaders and employers themselves, positive changes will emerge. Only then will cities disrupt the continuous, down-spiraling cycle of unequal representation and degree-attainment rates that exist between and within the nation's multicultural population and will educational institutions begin to leverage and support diversity as a social and economic asset. If encouraged to undertake broader responsibilities, the chief diversity officer with the support of college leadership holds enormous power to help change socio-economic disparities in America’s urban areas. 


\section{References}

Bonnabeau, R. F. (1996) The promise continues: Empire State College, The first twenty-five years. Virginia Beach, VA: The Donning Company Publishers

College completion: Who graduates from college, who doesn't, and why it matters. (2015) The Chronicle of Higher Education Report on College Completion. Retrieved from http://collegecompletion.chronicle.com/state/\#state=ny\&sector=public_four

Swanson, C.B. (2008, April 1). Cities in crisis: A special analytic report on high school graduation. NCLB Implementation Report: State Approaches for Calculating High School Graduation Rates. Editorial Projects in Education. Retrieved from http://www.edweek.org/media/citiesincrisis040108.pdf 


\section{Author Information}

Merodie Hancock is president of Empire State College, State University of New York. She has dedicated her career to expanding access to higher education for nontraditional students via innovative classroom and residency-based, online, and independent-study learning across distributed campuses in urban, suburban, rural and virtual locations, as well as international borders, and for military and veteran students. Hancock also established the first comprehensive, college-wide diversity, equity, and inclusion initiative at the college.

Merodie A. Hancock

President, Empire State College, State University of New York

2 Union Ave., Saratoga Springs, N.Y. 12866

Merodie.Hancock@esc.edu

518-587-2100 